Article

\title{
An Ontology of the Appropriate Assessment of Municipal Master Plans Related to Sardinia (Italy)
}

\section{Corrado Zoppi * and Sabrina Lai}

Department of Civil and Environmental Engineering and Architecture, University of Cagliari, Via Marengo 2, Cagliari 09123, Italy; E-Mail: sabrinalai@unica.it

* Author to whom correspondence should be addressed; E-Mail: zoppi@unica.it; Tel.: +39-070-675-5216; Fax: +39-070-675-5215.

Received: 6 March 2014; in revised form: 26 March 2014 / Accepted: 11 April 2014 / Published: 23 April 2014

\begin{abstract}
This paper discusses some key points related to the ontology of the "appropriate assessment" [1] procedure concerning plans significantly affecting Natura 2000 sites. We study this ontology by discussing its implementation into the adjustment process of the master plans of the regional municipalities of Sardinia (Italy) to the Regional Landscape Plan (RLP) and put as evidence some important general observations, coming from the case study, concerning the utility and effectiveness of the ontological conceptual framework in order to help planners and decision-makers understand and structure the assessment process of plans.
\end{abstract}

Keywords: ontology; ontologies; municipal master plans; appropriate assessment; Habitats Directive

\section{Introduction}

A very important issue concerning the preparation and approval of municipal master plans that may potentially affect sites of European Importance belonging to the so-called Natura 2000 network is represented by the appropriate assessment (AA) of the impacts of the master plan on the sites.

Within the framework of the adjustment process of municipal master plans to the Regional Landscape Plan of Sardinia and after providing the reader with a thorough presentation of both the normative standpoints for the AA and a discussion on the semantics of the term "ontology" (Section 2), this paper discusses some key points concerning the ontology of the AA procedure applied to master 
plans, using a sustainability-based methodology, and of its use in planning theory and practice (Section 3). This discussion regards the implementation process defined by the methodological guidance of the European Commission as an experimental context, with the objective of proposing the AA ontology as an important contribution to the improvement of AA effectiveness (Section 4).

We develop the ontology on the basis of these normative standpoints and implement its construction through Protégé, a software program developed by the Stanford Center for Biomedical Informatics Research of Stanford University [2].

\section{The Case Study}

With its approximately 24,000 square kilometers, Sardinia is the second-largest island in the Mediterranean Sea; its population density is rather low (slightly above 68 people per square kilometer), as it counts less than 1.7 million inhabitants according to the 2011 National Census. The vast majority of Sardinians live close to the sea and especially in the two densely urbanized areas around the two major cities (Cagliari and Sassari), while the inner areas of the island, hilly and mostly badly connected to the rest of the island, are sparsely populated. This uneven concentration of population parallels the island's unbalanced economic development, as in coastal areas, the majority of economic activities takes place.

It is therefore not surprising, given this context, that the Regional Landscape Plan of Sardinia (RLP), the first statutory landscape plan with regional dimensions produced in Italy under the new legislation, focused on the coastal zone, because of the complexity of the development conflicts arising from tourism (on which a large part of the economy of the island relies) and other development and owing to the fact that thirteen out of the fourteen previous landscape plans covering coastal areas, which contained some restrictions on coastal development, had been quashed in a two-step, five-year long process (1998-2003), some by the President of the Italian Republic and the remaining by the regional administrative court.

Following approval of the plan in 2006, restrictions and prohibitions (on the development of land and on certain changes in land uses) stemming from the plan are currently in force, in order to protect a part of the island considered economically strategic and environmentally sensitive. Restrictions and prohibitions are set out by the plan by means of a system of rules.

The planning activity of the regional administration of Sardinia has undergone a deep change after the approval of the RLP, which establishes the directions for nearly any future planning activity in Sardinia and requires that actual sectoral and local plans, as well as plans for protected areas, be changed to comply with its directions.

The process of adjustment of the municipal master plans (MMPs) of the cities of the coastal strip to the RLP is quite complicated. The MMPs have to conform themselves to the descriptive, prescriptive and propositive contents of the RLP, to the general planning rules and directives established by the RLP for the coastal zones and to the strategic policies for the "conservation and protection, maintenance, improvement or restoration of the landscape values identified in the landscape units" [3].

The question of the adaptation process of the actual MMPs to the RLP is of paramount importance for the effectiveness of the new planning policies of the Sardinian regional administration and for the definition of a general model for the strategic assessment of city planning based on the analysis of the 
perceived needs and expectations of local communities, through sustainable-development-oriented governance processes [4].

\section{Background}

\subsection{The Appropriate Assessment of Municipal Master Plans}

A very important issue concerning the adjustment process of a municipal master plan to the RLP is represented by the appropriate assessment (AA) of the impacts of the master plan on Natura 2000 sites [5]. The discussion proposed in this paper focuses on the implementation of AAs within the master plan processes.

There are three main normative points of reference for the assessment of the impact of the adjustment process of the master plans of Sardinian municipalities to the RLP on the Natura 2000 sites: (i) the methodological guidance on the provisions of Articles 6(3) and (4) of the Habitats Directive 92/43/EEC “Assessment of plans and projects significantly affecting Natura 2000 sites" [6]; (ii) the guidance document on Article 6(4) of the "Habitats Directive" 92/43/EEC "Clarification of the concepts of: alternative solutions, imperative reasons of overriding public interest, compensatory measures, overall coherence, opinion of the commission" [7]; (iii) the provisions of [8], which are entirely related to the assessment of the impacts of master plans on Natura 2000 sites.

\subsection{From "Ontology" to "Formal Ontologies"}

A generally-accepted meaning of the term "ontology" in contemporary theoretical debates of urban and regional planning is the "discussion of the substance of an object," that is a discussion of the most important characteristics of its essence, especially in epistemological debates. For instance, Hillier [9] points out that, according to some contemporary scholars, "ontology" indicates the paradigm of "relational ontology," that is a discussion of the substance of the relations between agents and structures (capital, social classes, agreed-upon semantics, etc.) which do not possess their own essence, formed only through their being in relation. Moreover, Hillier stresses, with reference to DeLanda [10], that the reference point of planning practice should be the observation and analysis of the relations between the elements that constitute the empirical reality (e.g., agents and structures), whose existence does not depend on the fact that human beings perceive it.

These relations generate emergences, that is unexpected phenomena, for those who are familiar with the single elements, but who are not aware of their mutual relations, as well: the ontology of agents, structures and relations is a "realistic ontology" of the scientific paradigm of the (planning) disciplinary paradigm, which is based on the empirical analysis of the relation. These emergences have an autonomous existence with respect to agents and structures.

The realistic ontology (the ontology of relations) is an ontology of reality [9], and a scholar's disciplinary role is to be aware of and to describe this reality, by identifying and analyzing its relational substance.

The "substantial" attribute of the term "ontology" leads to an effective comprehensive view of the contemporary debate concerning ontology and ontologies. In this context, ontology is not referred to, according to the meaning described so far, as one or a set of conditions that define the substance of a 
concept (reality-agents, structures, relations), as much as the substance of its agreed-upon representation, that is its formal definition. Ontology is the identification of a concept, of a domain; in other words, the cognitive contents that a set of agents identify as the particular characteristics of a domain. Therefore, ontology is not connected to substance, that is the essence of an object, as much as to the agreed-upon available knowledge (scientific, technical, based on traditions and on common sense, etc.) concerning an object.

Formal ontologies are not connected to substance or to essence, but to the essence of representations, or definitions; that is, they propose an agreement on cognitive contents, rather than the substance analysis of an object. According to Smith [11], ontologies are descriptions of domains of objects as closed data models, whose nodes define concepts. These concepts are strategically identified and make sense only in the context of the universe they try to model. Moreover, Smith illustrates that, historically, the use of formal ontologies comes from the fact that several disciplines are experiencing a dramatic Tower of Babel syndrome, which needs to be addressed somehow. Those who deal with complex systems of data and knowledge have peculiar and often idiosyncratic frameworks for representing information. The semantics used for the same term may vary or the semantics for different terms could take the same meanings. Formal ontologies could make it easier to deal with this syndrome.

Furthermore, according to Guarino [12], as quoted by Pretorius [13], a formal ontology is a projected representation that consists of a specific agreed-upon set of words that describe concepts belonging to a knowledge domain and a set of agreed-upon propositions concerning the meanings of these words, as well. Guarino also discusses the issue of the logical and axiomatic rules behind ontologies [14]. Pretorius agrees with Smith since, in his view, the concept of ontology originated in the field of artificial intelligence. Falquet et al. [15] and Bhatt et al. [16] treat ontologies applied to the semantics of urban environments. The different perspectives on ontologies presented above are summarized in Table 1.

Table 1. The semantics of the word ontology. A summary of different perspectives.

\begin{tabular}{ll}
\hline Ontology & A discussion of the substance of an object \\
\hline Relational ontology & $\begin{array}{l}\text { A discussion of the substance of the relations between agents and structures } \\
\text { (capital, social classes, agreed-upon semantics, etc.), which do not possess their } \\
\text { own essence, formed only through their being in relation. }\end{array}$ \\
\hline Realistic ontology & The ontology of the system of relations, i.e., an ontology of reality. \\
\hline Formal ontology & A discussion on the substance of an agreed-upon representation. \\
\hline
\end{tabular}

In the remainder of this paper, when we use the word "ontology," we refer to formal ontology, since within the context of spatial planning, they have generally been proposed as a means to share and reuse existing information and data [17], to homogenize data and solve semantic conflicts [18], to support the modeling of spatial datasets [19] and, therefore, as a possible solution to the issue of making interoperability and integration possible in spite of the proliferation of data and data sets built in the absence of common standards [20]. One of the most challenging and promising fields of research concerning the use of ontologies in spatial planning deals with allowing for a better understanding and awareness of programming and planning processes [21]. Ontologies, in this context, do not deal with 
"the specification of what exists and what does not exist, but rather with the creation of a data set that contains concepts related to the domain under inquiry" [22]; in other words, they tackle the problem of describing a given domain of interest by identifying key concepts that define the domain, relations that connect the concepts and existing constraints, thus making formalization and knowledge sharing within the given domain possible.

There are many definitions of the word "ontology" in the literature regarding the field of artificial intelligence [23]. As Caglioni and Rabino [24] point out, there is no single definition, and conceptual definitions "that regard ontology as a reference system for knowledge" coexist with "others, more operational, which lay the grounds for their actual construction, development and use." One of the most used and most frequently cited definitions is Gruber's [25], for whom an ontology is an "explicit specification of a conceptualization": this conceptualization, or in other words, the construction of an abstract and simplified conceptual model of a given object, or phenomenon, or process represented by the ontology, is explicit, because each concept, relationship and constraint is explicitly defined. The subsequent definition by Studer et al. (a "formal, explicit specification of a shared conceptualization" [26]), enriches Gruber's with two additional requirements: first, an ontology should be formal, that is machine-readable; in addition, the conceptual model of the object being represented needs to be agreed by a group of individuals [27], and therefore, the consensus of members of a given community is necessary.

\section{Methodology}

\subsection{The Appropriate Assessment Procedure under the Habitats Directive}

We discuss the AA of the municipal master plans of Sardinia on the basis of the provisions of the Methodological Guidance (MG) quoted above [6]. The MG is essentially related to Articles 6.3 and 6.4 of the Habitats Directive. The methodology for the AA implementation is described in the third section of the MG, even though only paragraph 2 defines the assessment phases, while the others concern the screening procedure (paragraph 1), the issues of alternatives to the proposed plan or project that might possibly generate negative impacts on a Natura 2000 site (paragraph 3) and of how to deal with situations characterized by lack of alternative solutions and important negative impacts (paragraph 4).

The AA of a municipal master plan (MMPs) on the Natura 2000 site(s) located in the area ruled by the municipal administration ("Site" hereafter) is based on an information set related to the Site and to the rules of the MMPs concerning the municipal area that overlaps the Site (Site overlapping area, SOVLA).

According to the MG, a Site can be characterized through the following information set: (i) habitats; (ii) species; (iii) conservation objectives; (iv) ecological requirements; (v) threats, pressures and activities with impacts on the Site; and (vi) relevant conservation issues. This set contains information which, on the one hand, comes from the characterization of habitats, species and impacts contained in the Site's Natura 2000 Standard Data Forms (SDFs) available, for each Site, on the Internet site of the European Environment Agency concerning the Natura 2000 network [28,29]. On the other hand, supplemental information is required, which is related to conservation objectives, ecological requirements and relevant conservation issues. This information can be collected from several sources, such as scientific studies concerning site-specific historical, natural and environmental issues, on-site 
surveys related to the conditions of habitats and species and on the local factors, which may generate negative impacts, etc.

The SDFs contain detailed information on habitats and species, in compliance with the classification of the Habitats Directive. This includes habitats' and species' interpretation and representation elements. Habitats are classified into natural habitat types of community interest and priority natural habitat types [30]. Species of community interest are drawn from those listed in [31]. The informative content of the SDFs concerning habitats and species is defined as follows [32].

Information concerning interpretation and representation of habitats includes:

i. representativity, that is Criterion A.(a) of Annex III of the Habitats Directive: the representativity of an habitat for a Site is related to how a habitat is typical for the Site, and either for groups or for combinations of groups of habitats; the assessment of representativity should be implemented taking account of the provisions of the Interpretation Manual issued by the DG Environment of the European Commission [33];

ii. relative surface, that is the ratio of the area of the habitat in the Site to the total area covered by that habitat type within the national territory; that is, Criterion A.(b) of Annex III;

iii. state of conservation in terms of structure and functions and restoration possibilities, that is Criterion A.(c) of Annex III;

iv. global assessment of the habitats, with reference to the three criteria indicated above, that is Criterion A.(d) of Annex III.

Information concerning the interpretation and representation of species includes:

i. population of the species in terms of the ratio of the number of individuals with respect to the total population within the national territory, that is Criterion B.(a) of Annex III;

ii. conservation of the species, in terms of the state of conservation of the Site's habitat elements relevant for the species, which is related to the elements' state of conservation and to the restoration possibilities, that is Criterion B.(b) of Annex III;

iii. isolation of the species, which indicates the species' potential contribution to biological diversity, that is Criterion B.(c) of Annex III;

iv. global assessment of the species, with reference to the three criteria indicated above, that is Criterion B.(d) of Annex III.

Moreover, the SDFs contain precise information, which could possibly be expanded within the AA, on threats, pressures and activities with impacts on the Site.

The other three elements of the information set on the Site need particular attention in terms of Site-specific scientific research and direct observation and surveys. The greater part of this information should be included in the management plans of the Site, if available [34]. The greater part of the Sardinian Sites of Community Interest are ruled by management plans, which received huge financial support from the Sardinian regional administration during the 2000-2006 European Union Structural Funds programming period; the preparation of a series of management plans also concerning Special Protection Areas, funded through the 2007-2013 Rural Development Program (Measure 323, Action 1, Sub-action 1), is currently in progress. Thus, the information set could be made almost complete for the greater part of the Sardinian Sites with little supplemental effort. 
The SOVLA of the MMPs concerning a Site is characterized by the following information: (i) zone-type according to the PIC of the MMPs; and (ii) habitats included in the SOVLA. Industries and services to the population are taken into account in the zoning scheme of the master plan, and, as a consequence, in the SOVLA; therefore, if the provisions of the PIC imply possible future residential, service or infrastructure-related development in the SOVLA, negative impacts on habitats and species can eventually take place as a result of the interaction between planning rules, conservation objectives and ecological requirements.

The AA, according to the MG (subparagraph 5 of paragraph 3.2. and paragraphs 3.3. and 3.4.), has to define and make available to planners, public officers, decision-makers and local communities a set of possible policies to: (i) mitigate the negative impacts of the on-going land-use developments and transformations; (ii) delineate possible future scenarios alternative to the present that are generating negative impacts on habitats and species; and (iii) address situations characterized by a lack of alternatives and the persistence of negative impacts.

From this perspective, the AA is quite similar to an environmental report of the strategic environmental assessment of an MMP, which should include measures that in some way address the issue of negative impacts on environmental resources [35]. As in the case of the environmental report, the fundamental question to be analyzed is how and by how much the implemented MMPs affect and impact both the ecological requirements and conservation objectives of the Site. Hence, not only is it fundamental to understand and design a proper framework concerning the Site and its characteristics, requirements and objectives, but it is also decisive to build a proper conceptual model of the interaction between the plan implementation, particularly in the SOVLA, and the habitats and species of the Site.

The fundamentals of the ontology of AA processes concerning MMPs should entail: (i) analysis and interpretation of the Site, that is the characterization of the Site in terms of habitats, species, ecological requirements and conservation objectives; (ii) a definition of the implementation code of the MMPs concerning the SOVLA; and (iii) the conceptualization of the interaction between MMPs and the Site. In the following section, we propose tentatively an ontology having these features.

\subsection{Ontologically Framing the Appropriate Assessment Procedure}

The ontology of the domain "appropriate assessment of municipal master plans" was developed according to the phases suggested by guidance documents and methodological reports produced by the Ordnance Survey, according to which the process whereby an ontology is built can be broken down into a series of steps, the first being the identification of the purpose of the ontology (i.e., the specification of needs and requirements that the ontology should be able to fulfill) and of its scope (i.e., a delimitation of the domain under investigation). These two aspects are crucial for ensuring both that the ontology is correctly formalized and that it is useful, meaning that it contains only those concepts, relationships and constraints that are judged to be relevant, with regard to the possible ways in which the ontology can be used. With reference to the first point (purpose), the ontology here proposed aims to represent the appropriate assessment as a process; in particular, it must explain the key concepts of the AA in the special context of land-use planning, and ideally, it should guide plan-making by providing planners with a framework for the identification and understanding of the 
likely impacts of plan contents and provisions on Natura 2000 sites. With reference to the second point (scope), the domain is here confined to the appropriate assessment of MMPs.

Once the purpose and scope have been established, the following step consists of the construction a glossary ("knowledge glossary"), comprising two tables. The first table ("table of concepts") contains a list of core and secondary concepts together with their definition in natural language, the indication of the source of the definition and of possible synonyms. Concepts can be either core concepts or secondary concepts, depending on whether or not they are included in the domain under investigation, that is, ultimately, on how purpose and scope have been defined in the previous step. Core concepts are deemed necessary to represent the domain; on the contrary, secondary concepts are not part of the domain; however, they belong to the glossary, because they need to be defined in order to describe core concepts. The second table ("table of relations") lists and defines, again, in terms of natural language only, relationships between concepts pertaining to the domain.

\section{Results}

The definition of concepts and relationships was based on documentary sources only. These comprised relevant European Directives, as well as national and regional pieces of legislation (e.g., the already mentioned Habitats and Bird Directives, the Decree of the President of the Italian Republic No. 357 of 1997, as amended by Decree 120 of 2003, which translates the Habitats Directive into the Italian legislation) and of technical documents, such as the three main points of reference already cited in the introduction to this paper [6-8]; plus other documents deemed of interest [36-38]. The use of such sources (accounted for in Table 2, which illustrates a part of the table of concepts) was an attempt to ensure that definitions are agreed upon by, and shared among, domain experts, although it is important to note that unanimous agreement in some aspects is impossible to achieve, be it for internal ambiguities in the sources used or for the mere fact that various interpretations of a given phenomenon coexist. As an example of the first type, let us consider the concept "Impact": since the definition given by the European Commission (third row in Table 2) is extremely broad, a classification of impact types provided by the European Environment Agency and built by experts in the field of nature conservation was also used (fourth row in Table 2); some items in the list leave room for ambiguity, as in the case of the item, J01 ("fire and fire suppression") [39]. As an example of the second type and quite important to the domain analyzed here, the identification of habitat types protected under the Habitats Directive is a matter of interpretation, which, in some cases, brings about not only the differences among member states [40], but also among experts working in the same region [41].

Through a series of checks at the internal level of definitions and relations, the two tables were enhanced and modified recursively.

The knowledge glossary, in spite of its being an explicit and shared (at least, potentially) specification of the entities that constitute the abstract and simplified model of the AA process developed in light of the documentary sources examined, is not a formal specification of the domain, up to this point. For the computational aspects, the software program, Protégé, was used [2]; concepts previously merely listed in the knowledge glossary were next arranged in Protégé in a hierarchical manner, that is they were organized and grouped into classes and subclasses on the basis of the relationship "is a". To state that a given element belongs to a subclass of a class is in fact tantamount to 
affirming that this element belongs to the class and, therefore, that it inherits its properties. In this way, key concepts identified in the previous phase were first organized in a taxonomy according to the following classes: "Site", "Habitat", "Species", "Conservation objectives", "Impacts", “Overlap zones", "Zone type" and "Overlap zone", and then, the corresponding definitions were inserted for each class and subclass.

Table 2. Knowledge glossary: table of concepts. An extract only showing some of the core concepts.

\begin{tabular}{|c|c|c|}
\hline Core concept & Definition & Source \\
\hline $\begin{array}{l}\text { Conservation } \\
\text { objectives }\end{array}$ & $\begin{array}{l}\text { A conservation objective is the specification of the overall target for the species and/or } \\
\text { habitat types for which a site is designated in order for it to contribute to maintaining or } \\
\text { reaching a favorable conservation status of the habitats and species concerned, at the national, } \\
\text { the biogeographical or the European level. }\end{array}$ & [36] \\
\hline Habitat & $\begin{array}{l}\text { Natural habitat means terrestrial or aquatic areas distinguished by geographic, abiotic and } \\
\text { biotic features, whether entirely natural or semi-natural; } \\
\text { natural habitat types of community interest means those which, within the territory referred to } \\
\text { in Article 2: } \\
\text { (i) are in danger of disappearance in their natural range; or } \\
\text { (ii) have a small natural range following their regression or by reason of their intrinsically } \\
\text { restricted area; or } \\
\text { (iii) present outstanding examples of the typical characteristics of one or more of the nine } \\
\text { following biogeographical regions: Alpine, Atlantic, Black Sea, Boreal, Continental, } \\
\text { Macaronesian, Mediterranean, Pannonian and Steppic. }\end{array}$ & [42] \\
\hline Impact & $\begin{array}{l}\text { Impacts relate to all human activities and natural processes that may have an influence, either } \\
\text { positive or negative, on the conservation and management of the site. }\end{array}$ & [43] \\
\hline Impact type & $\begin{array}{l}\text { Impacts stemming from threats, pressures and activities - list in accordance with Article } 17 \\
\text { code list. }\end{array}$ & [44] \\
\hline Site & $\begin{array}{l}\text { Site of community importance means a site that, in the biogeographical region or regions to } \\
\text { which it belongs, contributes significantly to the maintenance or restoration at a favorable } \\
\text { conservation status of a natural habitat type in Annex I or of a species in Annex II and may } \\
\text { also contribute significantly to the coherence of Natura } 2000 \text { referred to in Article } 3 \text { and/or } \\
\text { contributes significantly to the maintenance of the biological diversity within the } \\
\text { biogeographic region or regions concerned. }\end{array}$ & [45] \\
\hline Species & $\begin{array}{l}\text { Species of community interest means species that, within the territory referred to in Article } 2 \text {, are: } \\
\text { (i) endangered, except those species whose natural range is marginal in that territory and } \\
\text { which are not endangered or vulnerable in the western Palearctic region; or } \\
\text { (ii) vulnerable, i.e., believed likely to move into the endangered category in the near future if } \\
\text { the causal factors continue operating; or } \\
\text { (iii) rare, i.e., with small populations that are not at present endangered or vulnerable, but are } \\
\text { at risk; the species are located within restricted geographical areas or are thinly scattered } \\
\text { over a more extensive range; or } \\
\text { (iv) endemic and requiring particular attention by reason of the specific nature of their habitat } \\
\text { and/or the potential impact of their exploitation on their habitat and/or the potential } \\
\text { impact of their exploitation on their conservation status. }\end{array}$ & {$[46]$} \\
\hline
\end{tabular}


Next, for each class and subclass, appropriate slots were defined and created. Slots can be used either to characterize the elements of a class by means of attributes of different types (for instance, string, integer, enumerated) or to describe the relationships between instances, which are defined as the elements belonging to a given class; in other words, features represent the finest level of granularity and form the basis of the hierarchy. Figure 1a illustrates, as an example, the slots assigned to the class "Site", "Name", "Area size" and "Ecological requirements" are three descriptive attributes, all required and all having single cardinality (meaning that only one value for each attribute is allowed); the type of the first and that of the third is "string" (meaning that any alphanumeric string is allowed), while that of the second is "float" as this attribute accounts for a site's land mass.

Figure 1. Slots in Protégé. (a) An example of descriptive and relational slots assigned to the class "Site" in Protégé. (b) A graphical representation of relations corresponding to these slots.

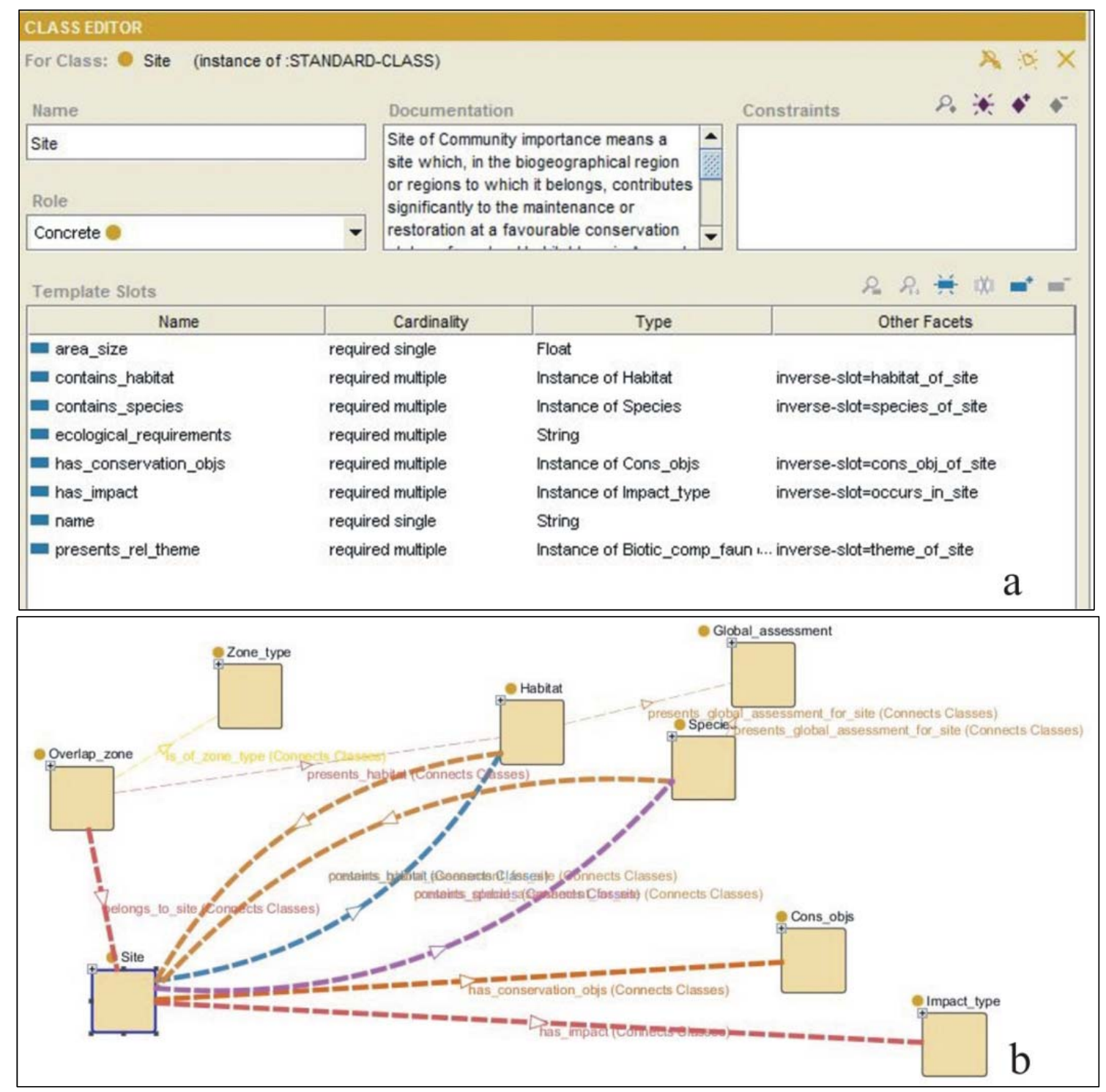

As far as the other five ("Contains habitat", "Contains species", "Has conservation objectives", "Has impact", "Presents relevant theme") are concerned, they make the relations between the class 
"Site", on the one hand, and, respectively, the classes, "Habitat", "Species", "Conservation objectives", "Impacts" and subclasses of the class "Phenomena", on the other hand, explicit, or more precisely, they make the relations between features belonging to the aforementioned classes explicit. These relations are represented by means of graphs in Figure $1 b$.

All of the five slots have multiple cardinality (that is, an instance of the class "Site" can host more than one instance of the class "Habitat" or more than one instance of the class "Species"; it can have more than one conservation objective (which depend on both the types of habitats and species present in a certain site and on their conservation status in that site); it can be subject to more than one type of impact (as identified and listed in the site's SDF); and it is affected by a plurality of phenomena that need to be taken into account when assessing the plan's effect on the site. Inverse relations are also defined, as shown in Figure 1b).

The construction of the ontology continues with the creation of instances and the filling-in of the values of the slots, and this is done by entering these values in appropriate forms that prevent users from including values that are inconsistent with the ontological hierarchy previously defined. Figure 2 shows two examples of this phase.

Figure 2. Instances in Protégé. (a) An example of instance belonging to the class "Overlap zone" and (b) one belonging to the class "Impact type," also showing their slots filled out in Protégé.

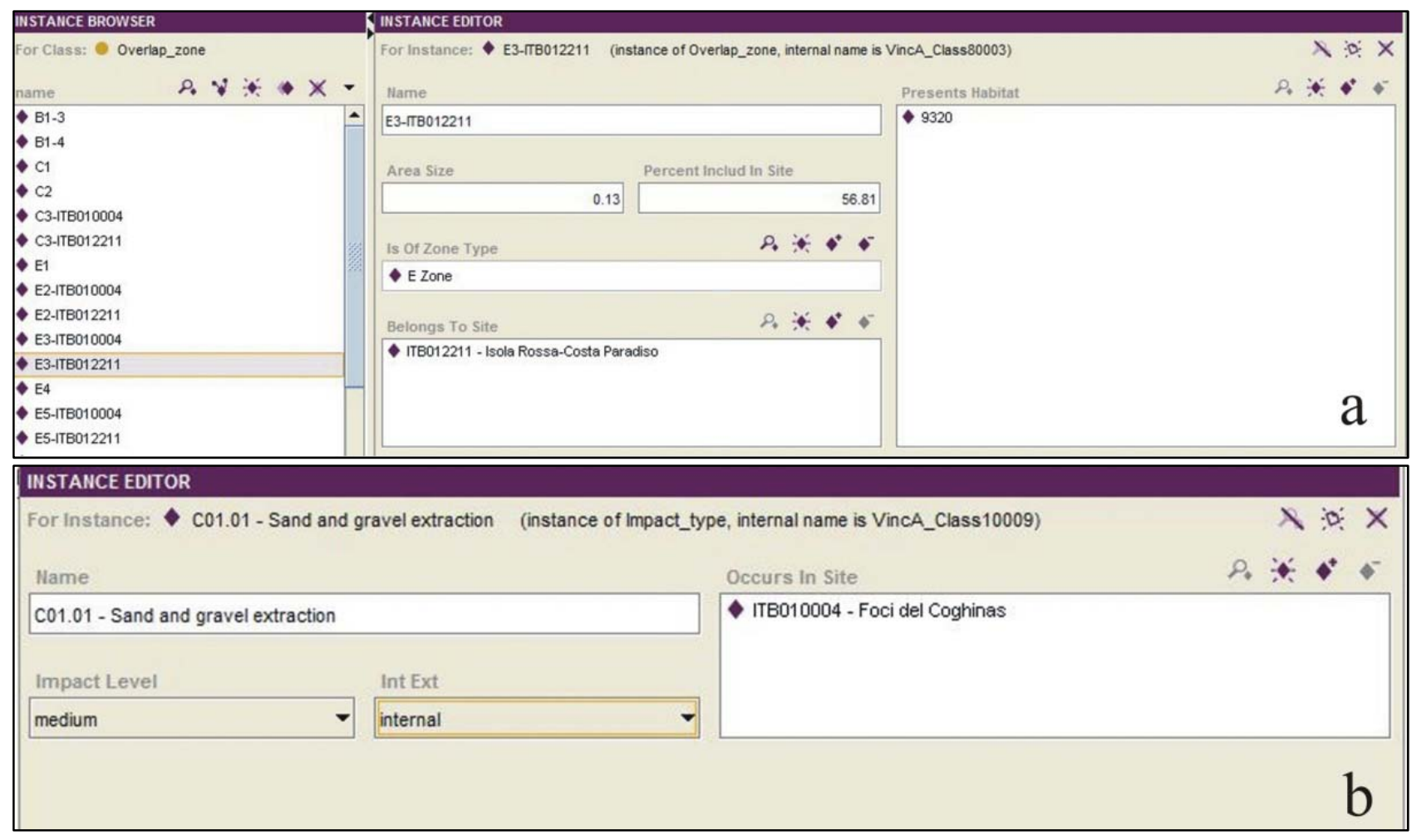

Once the instances have been created and their slots have been filled in, the ontology is fully and formally defined, even though it can be continually adjusted and integrated; moreover, the ontology can be represented graphically as a graph tree in which classes, subclasses and instances are represented as nodes and relations as arches, allowing users to navigate the whole hierarchy, or only a part (Figures 3 and 4). 
Graphs can be tailored to the user's needs, meaning that the user can choose whether to display all of the ontology, or only a part of it, by selecting the nodes to be represented or by filtering the relationships to be shown, which allows for a more effective and more understandable representation and exploration in case of complex ontologies.

Figure 3. Classes and subclasses of the domain in Protégé. Graph tree of the class "Phenomena," its subclasses and instances.

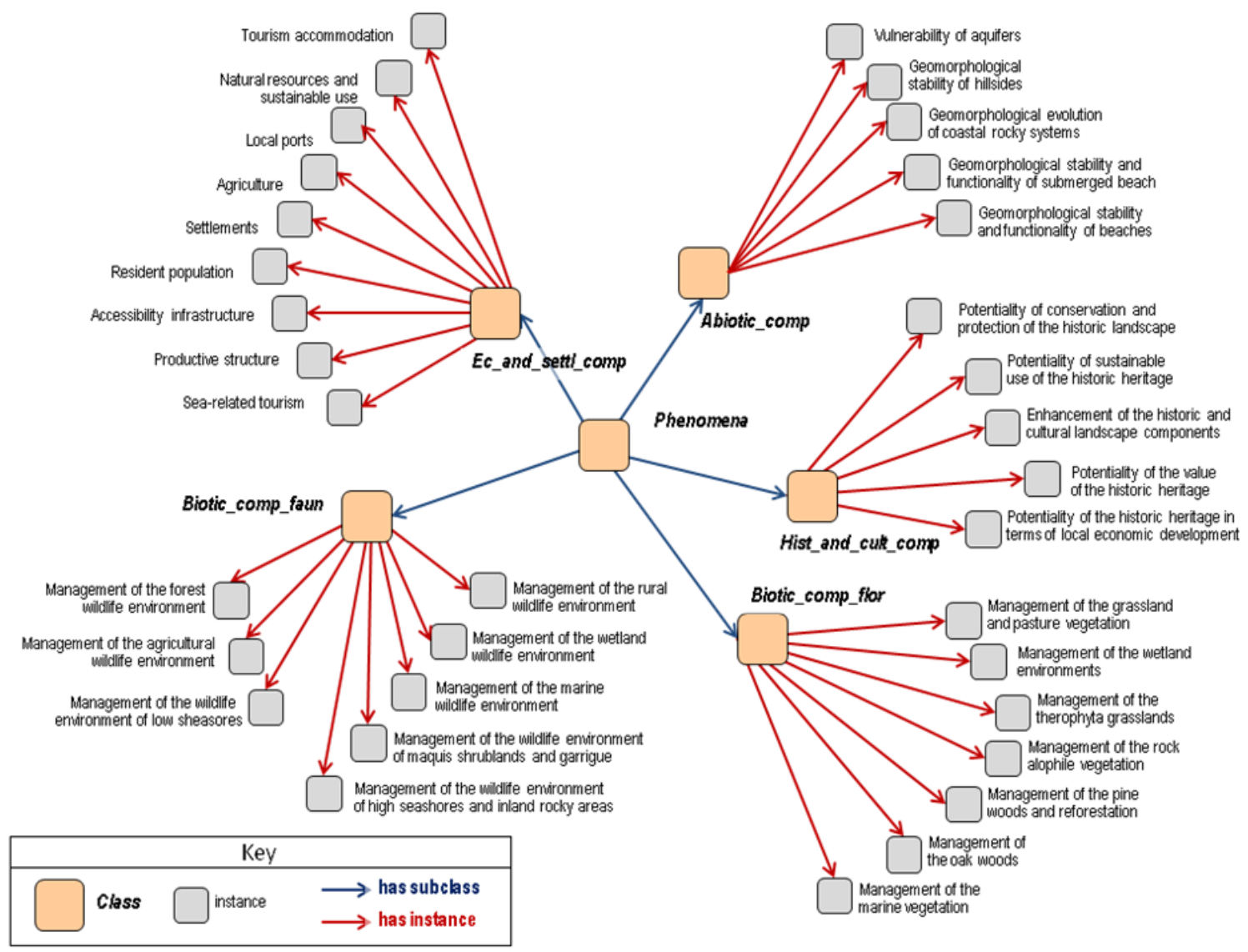

Figure 4. Classes and subclasses of the domain in Protégé. A graph tree showing the qualitative intensity of relationships between classes.

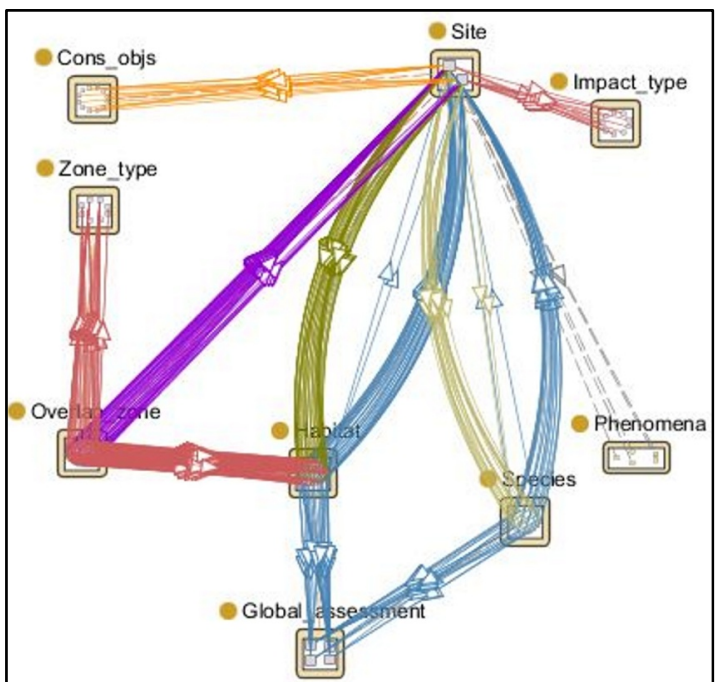




\section{Concluding Remarks: Discussion and Outlook}

This paper has attempted to build an ontological representation of the process of defining the AA of an MMP, based on the interpretation of the technical implementation into the praxis of legislative and normative acts and documents. The ontology can be useful for at least two reasons. First, this approach provides all the participants involved in the AA process (be they institutions, organizations or private citizens) with a better understanding of the domain of interest [47], through an iterative learning process that can continually be refined; this learning process is, in principle, inclusive, because the construction of the glossary can be improved by integrating the definition of concepts, relations and descriptive attributes, here carried out solely on the basis of documentary sources in a participative way, by including, for instance, experts in the domains of ecology, botany, zoology, planning and environmental assessment, or representatives of the public administrations involved. Such a collective conceptualization of the domain would also greatly improve the chances of sharing and reusing the ontology in the domain field.

Second, since the ontology here proposed is a domain ontology, therefore aimed at structuring, representing and communicating knowledge on a specific area of interest irrespective of potential applications, the ontology of the AA of MMPs can be updated, refined and reused in the given domain [27], and it can lay the bases for the development of task-dependent or application-oriented ontologies in the same domain, for instance focusing on administrative and procedural tasks. Table 3 shows the main pros and cons of the ontological approach we propose in this paper.

Table 3. The pros and cons of the ontological approach in planning processes. AA, appropriate assessment.

\begin{tabular}{ll}
\hline \multicolumn{1}{c}{ Pros } & \multicolumn{1}{c}{ Cons } \\
\hline $\begin{array}{l}\text { Better understanding of the domain through an iterative } \\
\text { learning process that can continually be refined. }\end{array}$ & $\begin{array}{l}\text { The ontology can be exported only to countries where the AA } \\
\text { procedure is in place. }\end{array}$ \\
\hline $\begin{array}{l}\text { Inclusiveness of different and often non-consistent } \\
\text { disciplinary and scientific perspectives through the }\end{array}$ & $\begin{array}{l}\text { Exportability is constrained by differences in the institutional } \\
\text { spatial and regional planning frameworks to which the } \\
\text { participation of the experts in the involved domains or of } \\
\text { key stakeholders. }\end{array}$ \\
\hline Sharing and reusing opportunities in the given domain. & Issues of semantics owing to different institutional contexts. \\
\hline Possibility of continuous refinement and updating. & Issues of semantics due to the translation of the glossary. \\
\hline Exportability in the domain under the given conditions. & $\begin{array}{l}\text { Lack of mandatory character, which means that there is a } \\
\text { need for the establishment of a formal, regulatory framework. }\end{array}$ \\
\hline
\end{tabular}

Third, the ontology defined so far is designed with the general objective to make it easier and more effective to implement AA procedures, since it makes available a conceptual framework that allows planners and public officials to identify their roles and functions in the procedure development in a pretty straightforward way. For example, let us consider one of the central issues of the AA of an MMP, that is the question of the assessment of historic and cultural heritage. If we look at Figure 3, we can identify the instances of the subclass "Historic and cultural components" (notation "Hist_and_cult_comp") under class "Phenomena," namely, "Potentiality of conservation and protection of the historical heritage," "Potentiality of sustainable use of the historic heritage," 
"Enhancement of the historic and cultural landscape components," "Potentiality of the value of the historic heritage" and "Potentiality of the historic heritage in terms of local economic development." This part of the ontology gives planners and public officials a clear and distinct guideline on their assessment duty, which states that they have to characterize historic and cultural heritage in terms of the five instances above. Therefore, the ontology strengthens planners' and officials' awareness of how to act properly and effectively in the steering and implementation of assessment processes.

Fourth, it is worth discussing the ontology's validation issue. The ontology we discuss in this essay follows the provisions of the $\mathrm{MG}$, and by doing so, it is formally consistent with the technical requirements of the AA procedure of Articles 6(3) and (4) of the Habitats Directive; and as a consequence, it is valid and exportable, as it is, to other municipal contexts. The validation of our ontology is related to the following conditions [48]: (i) the hierarchies and relationships are complete, since the competency questions and the goal or purpose defined in the requirements stage at the beginning of the methodology (Articles 6(3) and (4) quoted above) are properly addressed in the ontology development; (ii) the model is internally consistent (no cyclicity of concepts, conflicting relationships and ambiguity in the definition of concepts do show up); and (iii) the ontology is entirely consistent with the initial documents, that is the documents related to the three normative points listed in Subsection 2.1. However, it has to be taken into account that AA is defined by the Habitats Directive as an incremental process, and as a consequence, its definition is dynamic and must comply, incrementally, with scientific, technical and normative advancements. Therefore, validation and completeness issues should be considered in the context of a continuous evolution of the AA practice.

Fifth, AA is a participatory, cooperative and incremental process, which aims at continuously improving the quality and effectiveness of MMPs. Therefore, a motivated statement issued by an AA authority who did not take part in the decision-making process of a plan, whose statement would be entirely analogous to the compatibility statement that concludes the Environmental Impact Assessment process of a project, should not be the desirable end of an AA process. An adequate AA process should rather be characterized by the active participation of each public administration sector involved, all of which should share their opinions, project objectives, procedures and policies concerning the future local economic and social development. The AA process is cooperative and inclusive ad intra in that its stakeholders belong to public administration, but at the same time, it should entail the implementation of an analogous implementation ad extra, that is one that involves the local communities. Therefore, the most important ontological characteristics of AA are cooperation between AA and planning public authorities and participation and inclusion of the private stakeholders in the assessment of MMPs. The participatory/inclusive AA process should imply continuous feedback on the implementation status of planning policies. In this process, all of the participants should improve their knowledge of the plan, its environmental impacts and how its policies address the territorial issue at stake. The public and private participants' cooperative attitudes should improve through the AA, as well [49]. Increased social learning, both in qualitative and quantitative terms, is one of the most important outcomes of endogeneity and participation/inclusion. In the ontology discussed in this essay, participation can be effectively embedded in the AA process at the stage of the definition of the instances of classes and subclasses. Instances are the core of the assessment procedure, since their contents are decisive to define prescriptions (e.g., denial of development permits) and mitigation measures. In a participatory and inclusive framework, these contents should be the results of 
negotiation processes, which should involve public administrations, the private sector (profit and non-profit) and the local communities. The presence of an agreed-upon ontology would help a lot to make negotiation more efficient, effective and time saving. The study of the implementation of ontology-based participatory processes related to AA of MMPs is a promising field for future research.

Sixth, the ontological representation of the domain "AA of MMPs" by providing a common vocabulary of the concepts of interest and a shared representation of their relations generates knowledge and makes it available to the end users [50], that is to planners, planning authorities and local stakeholders. This knowledge relates, at least partially, to spatial entities and spatial phenomena (such as Natura 2000 sites, habitats distribution, zoning schemes); therefore, its formalization could improve the implementation of a spatial data infrastructure compliant with the INSPIRE Directive [51] to support environmental assessment in spatial planning, as it allows for interoperability and minimizes possible problems with data integration, which is the primary use of ontologies in GIS science [27].

Last, but not least, a strong point of this paper is that the ontological approach utilized here can be readily exported throughout the countries where an AA of MMPs is required in compliance with the Habitats Directive; however, the domain ontology developed here is grounded on the normative framework that regulates MMPs in Italy, and as a consequence, some adjustments would be necessary so as to reuse this ontology to describe the AA procedure in Member states of the European Union other than Italy. Another important limitation to the exportability of the ontology in other contexts lies in the fact that the definitions of concepts are based, at least to some extent, on Italian laws and regulations, technical documents and vocabularies; for this reason, the table of concepts presented here was partially built in Italian in the first place and, afterwards, translated into English, which can cause some issues of semantic precision in English. Finally, in light of the effectiveness of the ontological approach to the definition and implementation of plan appraisal procedures, until this approach (which is voluntary and, as of now, not widespread) becomes steadily embedded in planning practice, the implementation of structured ontology-based planning processes needs the establishment of a formal, regulatory framework that would make this approach mandatory, at least at some stage of the decision making process. The advantages and drawbacks of the use of ontologies in plan appraisal processes are summarized in Table 3.

\section{Authors' Contributions}

Sabrina Lai and Corrado Zoppi have made substantial contributions to the essay's conception and design, background and concluding remarks. Corrado Zoppi defined the normative framework of the appropriate assessment (AA) of municipal master plans (MMPs). Sabrina Lai designed the implementation of the formal ontology related to the AA of MMPs.

\section{Conflicts of Interest}

The authors declare no conflict of interest. 


\section{References and Notes}

1. The Habitats Directive; Under Directive 92/43/EEC of May 21, 1992; European Commission: Brussels, Belgium, 1992.

2. Protégé, Version 3.4.7; Frame Oriented: Stanford Center for Biomedical Informatics Research, Stanford University. Available online: http://protege.stanford.edu/ (accessed on 18 April 2014).

3. Planning Implementation Code of the RLP (PIC), Article 7, Paragraph 1.

4. Cau, M.S.; Zoppi, C. L'adeguamento del Piano urbanistico del Comune di Sinnai al Piano paesaggistico regionale: il problema delle zone di espansione residenziale (The adjustment of the Masterplan of the City of Sinnai to the Regional Landscape Plan: the problem of the residential expansion zones). In Governance, Pianificazione e Valutazione Strategica. Sviluppo Sostenibile e Governance Nella Pianificazione Urbanistica (Governance, Planning and Strategic Assessment. Sustainable Development and Governance in City and Regional Planning); Zoppi, C., Ed.; Gangemi: Rome, Italy, 2008; pp. 299-312.

5. Natura 2000 is a European coherent network of areas to be protected for their ecological importance, and in Sardinia it presently consists of Sites of Community Importance and Special Protection Areas, as Special Areas of Conservation have yet to be established.

6. European Commission, DG Environment. Assessment of Plans and Projects Significantly Affecting Natura 2000 Sites. Methodological Guidance on the Provisions of Article 6(3) and (4) of the Habitats Directive 92/43/EEC; 2001. Available online: http://ec.europa.eu/environment/ nature/natura2000/management/docs/art6/natura_2000_assess_en.pdf(accessed on 18 April 2014).

7. European Commission, DG Environment. Guidance document on Article 6(4) of the "Habitats Directive" 92/43/EEC. Clarification of the Concepts of: Alternative Solutions, Imperative Reasons of Overriding Public Interest, Compensatory Measures, Overall Coherence, Opinion of the Commission; 2012. Available online: http://ec.europa.eu/environment/nature/natura2000/ management/docs/art6/new_guidance_art6_4_en.pdf (accessed on 18 April 2014).

8. Annex D of the Annex to the Deliberation of the Regional Government of Sardinia Autonomous Region No. 44/51, December 14, 2010.

9. Hillier, J. Introduction to Part Two. In The Ashgate Companion to Planning Theory; Hillier, J., Healey, P., Eds.; Ashgate Publishing Limited: Farnham, UK, 2010; pp. 235-250.

10. DeLanda, M. A New Philosophy of Society: Assemblage Theory and Social Complexity; Continuum: New York, NY, USA, 2006.

11. Smith, B. Ontology. In Blackwell Guide to the Philosophy of Computing and Information; Floridi, L., Ed.; Blackwell: Oxford, UK, 2003; pp. 155-166. Available online: http://ontology.buffalo.edu/ smith/articles/ontology_pic.pdf(accessed on 18 April 2014).

12. Guarino, N. Formal Ontology in Information Systems. In Proceedings of the First International Conference (FOIS'98), Trento, Italy, June 6-8 1998; Guarino, N., Ed.; IOS Press: Amsterdam, The Netherlands, 1998; pp. 3-15.

13. Pretorius, A.J. Ontologies-Introduction and Overview; 2004; p. 3. Available online: http://www.starlab.vub.ac.be/teaching/Ontologies_Intr_Overv.pdf (accessed on 18 April 2014). 
14. Guarino, N. The ontological level: revisiting 30 years of knowledge representation. In Conceptual Modeling: Foundations and Applications; Borgida, A., Chaudhri, V.K., Giorgini, P., Yu, E.S.K., Eds.; Springer-Verlag: Berlin, Germany, 2009; pp. 52-67.

15. Falquet, G.; Métral, C.; Teller, J.; Tweed, C.; Eds. Ontologies in Urban Development Projects; Springer-Verlag: Berlin, Germany, 2011.

16. Bhatt, M.; Dylla, F.; Hois, J. Spatio-terminological inference for the design of ambient environments. In Spatial Information Theory, 9th International Conference on Spatial Information Theory, COSIT 2009, Proceedings; Stewart Hornsby, K., Claramunt, C., Denis, M., Ligozat, G., Eds.; Springer-Verlag: Berlin, Germany, 2009; Lecture Notes in Computer Science, Volume 5756, pp. 371-391.

17. Noy, N.F.; McGuinness, D.L. Ontology Development 101: A Guide to Creating your First Ontology, 2007. Available online: http://protege.stanford.edu/publications/ontology_development/ ontology101.pdf (accessed on 18 April 2014).

18. Mizen, H.; Dolbear, C.; Hart, G. Ontology ontogeny: understanding how an ontology is created and developed. In Proceedings of the First International Conference on GeoSpatial Semantics, Mexico City, Mexico, 29-30 November 2005; Available online: http://citeseerx.ist.psu.edu/ viewdoc/download?doi=10.1.1.97.5100\&rep=rep1\&type=pdf (accessed on 18 April 2014).

19. Schuurman, N. Formalization matters: Critical GIS and ontology research. Ann. Assoc. Am. Geogr. 2006, 96, 726-739.

20. Murgante, B.; Scorza, F. Ontology and Spatial Planning. In Computational Science and Its Applications: ICCSA 2011, 1st ed.; Murgante, B., Gervasi, O., Iglesias, A., Taniar, D., Apduhan, B.O., Eds.; Springer-Verlag: Berlin, Germany, 2011; pp. 255-264.

21. Scorza, F.; Las Casas, G.; Murgante, B. Overcoming Interoperability Weaknesses in E-Government Processes: Organizing and Sharing Knowledge in Regional Development Programs Using Ontologies. In Organizational, Business, and Technological Aspects of the Knowledge Society, Communications, 1st ed.; Lytras, M.D., Ordonez De Pablos, P., Ziderman, A., Roulstone, A., Maurer, H., Imber, J.B., Eds.; Springer-Verlag: Berlin, Germany, 2010; pp. 243-253.

22. Las Casas, G.; Scardaccione, G. Rappresentazione concettuale della conoscenza: ontologia del rischio sismico. (A conceptual representation of knowledge: an ontology of seismic risk). In L'Informazione Geografica a Supporto della Pianificazione Territoriale (Geographic Information as a Tool to Support Spatial Planning); Murgante, B., Ed.; FrancoAngeli: Milan, Italy, 2008; pp. 279-299.

23. Winter, S. Ontology: Buzzword or paradigm shift in GI Science? Int. J. Geogr. Inf. Sci. 2001, 157, 587-590.

24. Caglioni, M.; Rabino, G.A. La costruzione di un'ontologia urbana condivisa e riutilizzabile (The Construction of a Shared and Reusable Urban Ontology). In Proceedings of the 27th Italian Conference of Regional Science AISRE, Pisa, Italy, 12-14 October 2006. Available online: http://www.grupposervizioambiente.it/aisre_sito/minisito_2006/cd_aisre/Paper/Caglioni.pdf (accessed on 18 April 2014). 
25. Gruber, T.R. Toward Principles for the Design of Ontologies Used for Knowledge Sharing; Technical Report KSL 93-04; Knowledge Systems Laboratory, Stanford University: Stanford, CA, USA, 1993. Available online: http://citeseerx.ist.psu.edu/viewdoc/download? doi=10.1.1.91.6025\&rep=rep1\&type=pdf (accessed on 18 April 2014).

26. Studer, R.; Benjamins, V.R.; Fensel, D. Knowledge engineering: principles and methods. Data Knowl. Eng. 1998, 25, 161-197.

27. Agarwal, P. Ontological considerations in GIScience. Int. J. Geogr. Inf. Sci. 2005, 19, 501-536.

28. Natura 2000 Network Viewer. Available online: http://natura2000.eea.europa.eu/ (accessed on 18 April 2014).

29. See the Commission Implementing Decision of 11 July 2011 concerning a site information format for Natura 2000 sites (notified under document C (2011) 4892).

30. Paragraphs 1 (c), 1 (d), and Annex I of the Habitats Directive.

31. Annexes II and IV of the Habitats Directive and Annex I of the Directive 2009/147/EC of November 30, 2009, the so-called Birds Directive.

32. Commission Implementing Decision C (2011) 4892; European Commission: Brussels, Belgium, 2011.

33. European Commission, DG Environment. Interpretation Manual of European Union Habitats EUR 27; 2007. Available online: http://ec.europa.eu/environment/nature/legislation/ habitatsdirective7docs/2007_07_im.pdf(accessed on 18 April 2014).

34. According to paragraph 1 of article 6 of the Habitats Directive: "For special areas of conservation, Member States shall establish the necessary conservation measures involving, if need be, appropriate management plans specifically designed for the sites or integrated into other development plans, and appropriate statutory, administrative or contractual measures which correspond to the ecological requirements of the natural habitat types in Annex I and the species in Annex II present on the sites."

35. Lai, S.; Zoppi, C. An ontology of the Strategic Environmental Assessment Procedure of City Masterplans. Future Internet 2011, 3, 362-378.

36. Commission Note on Setting Conservation Objectives for Natura 2000 Sites, 2012. European Commission Web Site. Available online http://ec.europa.eu/environment/nature/legislation/ habitatsdirective/docs/commission_note2.pdf (accessed on 18 April 2014).

37. Commission Note on the Designation of Special Areas of Conservation (SACs), 2012. European Commission Web Site. Available online http:/ec.europa.eu/environment/nature/legislation/ habitatsdirective/docs/commission_note.pdf (accessed on 18 April 2014).

38. Commission Implementing Decision of 11 July 2011 Concerning a Site Information Format for Natura 2000 Sites, 2011. EUR-Lex Web Site. Available online http://eur-lex.europa.eu/ LexUriServ/LexUriServ.do?uri=OJ:L:2011:198:0039:0070:EN:PDF (accessed on 18 April 2014).

39. Impact type code J01 is intrinsically ambiguous because does not make clear whether the impact is caused by the presence or by the absence of fire-The only way to disambiguate this item would be to use only its sub-codes (namely, J01.01"burning down," J01.02 "suppression of natural fires," J01.03 "lack of fires"); however this does not happen in several SDF's relating to Sardinian Sites, where code J01 can be found.

40. Evans, D. Interpreting the habitats of Annex I: past, present and future. Acta Botanica Gallica 2010, 157, 677-686. 
41. An example of habitat on whose interpretation experts disagree, at the regional level in Sardinia, is that coded priority habitat 6220 "Pseudo-steppe with grasses and annuals of the Thero-Brachypodietea," as also underlined in the Italian Interpretation Manual of Habitats of the Directive 92/43/EEC. Available online: http://vnr.unipg.it/habitat/cerca.do?formato=stampa\& idSegnalazione $=97$ (accessed on 18 April 2014).

42. Council Directive 92/43/EEC of May 21, 1992, on the Conservation of Natural Habitats and of Wild Fauna and Flora; OJ L 206, 7.22.1992, p. 7, Art. 1.c; European Commission: Brussels, Belgium, 1992.

43. Commission Implementing Decision of July 11, 2011, Concerning a Site Information Format for Natura 2000 Sites (notified under Document C(2011) 4892); (2011/484/EU), Para. 4,3. European Commission: Brussels, Belgium, 2011.

44. DG Environment, European Environment Agency (EEA). Reference List Threats, Pressures and Activities (Final Version). Available online: http://bd.eionet.europa.eu/activities/Natura_2000/ Folder_Reference_Portal/Ref_threats_pressures_FINAL_20110330.xls (accessed on 18 April 2014).

45. Council Directive 92/43/EEC of May 21, 1992, on the Conservation of Natural Habitats and of Wild Fauna and Flora; OJ L 206, 7. 22.1992, p. 7, Art. 1.k. European Commission: Brussels, Belgium, 1992.

46. Council Directive 92/43/EEC of May 21, 1992, on the Conservation of Natural Habitats and of Wild Fauna and Flora; OJ L 206, 22.7.1992, p. 7, Art. 1.g. European Commission: Brussels, Belgium, 1992.

47. Uschold, M.; Gruninger, M. Ontologies: principles, methods and applications. Knowl. Eng. Rev. 1996, 11, 93-155.

48. We follow the definition of validation and implied concept of completeness proposed on pp. 21-22 in: Hart, G.; Dolbear, C.; Goodwin, J.; Kovacs, K. Domain Ontology Development; Ordnance Survey Research: Southampton, UK, 2007.

49. Davoudi, S. La partecipazione nella pianificazione per la sostenibilità (Participation in Planning for Sustainability). Urbanistica 2003, 55, 119-129.

50. Fonseca, F.; Egenhofer, M.J.; Agouris, P.; Camara, G. Using ontologies for integrated information systems. Trans. GIS 2002, 6: 231-257.

51. Directive 2007/2/EC of the European Parliament and of the Council of 14 March 2007 Establishing an Infrastructure for Spatial Information in the European Community (INSPIRE). Available online: http://europa.eu/legislation_summaries/environment/general_provisions/ 128195_en.htm (accessed on 18 April 2014).

(C) 2014 by the authors; licensee MDPI, Basel, Switzerland. This article is an open access article distributed under the terms and conditions of the Creative Commons Attribution license (http://creativecommons.org/licenses/by/3.0/). 